\title{
Use of Blueberry to Study Genetic Control of Chilling Requirement and Cold Hardiness in Woody Perennials
}

\author{
Lisa J. Rowland and Elizabeth L. Ogden \\ Fruit Laboratory, Beltsville Agricultural Research Center, U.S. Department of Agriculture, Agricultural Research \\ Service, Beltsville, MD 20705 \\ Rajeev Arora and Chon-Chong Lim \\ Division of Plant and Soil Sciences, West Virginia University, Morgantown, WV 26506
}

Jeffrey S. Lehman

Department of Life and Earth Sciences, Otterbein College, Westerville, OH 43081-2006

\begin{abstract}
Amnon Levi
Vegetable Laboratory, Southern Region, U.S. Department of Agriculture, Agricultural Research Service, Charleston, SC 29414
\end{abstract}

Ganesh R. Panta

Department of Horticulture, University of Georgia, Athens, GA 30602

\begin{abstract}
The capacity of woody perennial plants to survive winter freezes is dependent on their entering a state of dormancy and developing cold hardiness (Powell, 1987). Once plants are in this winter dormant or "endodormant" state (Lang et al., 1987), a chilling period is required for vegetative and floral budbreak the following spring. This chilling requirement prevents growth from occurring during transitory periods of warm temperatures throughout a large portion of the winter and helps synchronize plant growth with exposure to favorable environmental conditions. Together, chilling requirement and cold hardiness levels determine to what degree temperate-zone fruit crops will survive the winter and early spring without shoot and flower bud damage.
\end{abstract}

Chilling requirement and cold hardiness play critical roles in determining winter and early spring survival in woody perennials. Even though these traits are important to fruit crop industries, the inheritance of genes controlling chilling requirement and cold hardiness has not been well studied and little effort has been made to identify and map the genes involved. One of the reasons for this is the difficulty of conducting genetic research in woody perennials. Factors such as long generation times and problems associated with inbreeding depression often render use of recombinant inbred lines and, sometimes, even use of true backcross and $\mathrm{F}_{2}$ populations impossible for genetic and mapping studies. Another reason for the lack of progress in this area is that the induction of dormancy and the development of cold hardiness occur simultaneously and are triggered by some of the same stimuli, such as increasingly shorter photoperiods and lower temperatures. Thus, discerning if certain physiological changes or changes in gene expression are actually associated with dormancy and/or cold hardiness can be exceedingly difficult.

We are using a combination of molecular, genetic, and physiological approaches to investigate genetic controls of chilling requirement and cold hardiness in blueberry (Vaccinium section Cyanococcus). In this paper, the term "cold hardiness" specifically refers to flower bud hardiness in the cold-acclimated state. The goals of our research are to: 1) construct a genetic linkage map of blueberry using diploid populations that segregate for chilling requirement and cold hardiness; 2) develop a better understanding of the modes of action of chilling requirement and cold hardiness genes, based on genetic analyses of

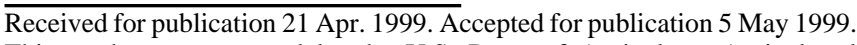
This work was supported by the U.S. Dept. of Agriculture-Agricultural Research Service, West Virginia Univ.-Agricultural Experiment Station, and the U.S. Dept. of Agriculture-National Research Initiative grant No. 9401825. West Virginia Univ. Agricultural Experiment Station Publication No. 2679. The cost of publishing this paper was defrayed in part by the payment of page charges. Under postal regulations, this paper therefore must be hereby marked advertisement solely to indicate this fact. gene action and quantitative trait loci (QTL) analyses, and tag genes controlling these traits. Concomitantly, we are trying to identify and isolate chilling/cold-responsive genes from blueberry and determine their relationship to dormancy and/or cold hardiness transitions. Here we describe the system (among blueberry populations) and the strategies used in our research, and discuss our progress in the research areas outlined above.

\section{WHY BLUEBERRY?}

There are several advantages to studying chilling requirement and cold hardiness in blueberry. In a recent survey of blueberry research and extension scientists in the United States, lack of cold hardiness and susceptibility to spring frosts were identified as the most important genetic limitations of current cultivars (Moore, 1993). At least eight different state and national breeding programs have as one of their goals either the development of new low-chilling blueberry cultivars for the southern United States or more cold-hardy blueberry cultivars for the northern United States. For the last several decades, one emphasis of the U.S. Dept. of Agriculture (USDA) Fruit Laboratory blueberry breeding program, as well as of similar programs in Florida, Georgia, North Carolina, Mississippi, Arkansas, and Texas, has been to develop hybrid highbush cultivars with low chilling requirements. Most of the cultivars are predominantly $V$. corymbosum L. but with the very low-chilling diploid species $V$. darrowi Camp in their parentage. Such hybrids should be suitable for growing in the southern United States, because they are earlier ripening than the rabbiteye cultivars grown there (Galletta and Ballington, 1996; Hancock and Draper, 1989). Other breeding programs, in Minnesota for example, have been developing more cold-hardy cultivars for the northern United States by hybridizing northern lowbush and highbush species to produce half-high types (Finn et al., 1990; Luby et al., 1986).

In addition to the importance of both chilling requirement and cold hardiness to the blueberry industry, there are other advantages to using blueberry plants for these studies. Blueberry is a small-statured fruit crop amenable to greenhouse and growth chamber experimentation, making it more suitable than most tree fruit species for studies of chilling requirement and cold hardiness. The genome (2C) is small $\left(\approx 1.2 \times 10^{9} \mathrm{bp}\right)$ relative to that of plants like maize (Zea mays L.) and tomato (Lycopersicon esculentum Mill.) (Costich et al., 1993), simplifying any future attempts at marker-based cloning. Genotypes, both wild and cultivated, range in ploidy levels from diploid to hexaploid. There is essentially no sterility barrier between species (Galletta and Ballington, 1996) and ploidy manipulations are well tolerated. The cluster-fruited blueberries appear to be an autopolyploid group displaying bivalent pairing, so homologous chromosomes from different species can pair and segregate normally (Hokanson and Hancock, 
1993; Krebs and Hancock, 1992; Qu and Hancock, 1995, 1997). Consequently, interspecific hybrids can be easily generated and used for developing segregating mapping populations. Production of $2 \mathrm{n}$ gametes at a relatively high frequency in some diploid species, such as V. darrowi (Draper et al., 1982; Ortiz et al., 1992), has allowed interspecific tetraploid hybrid populations to be generated from diploid $\mathrm{x}$ tetraploid $\mathrm{F}_{1} \mathrm{~s}$. We have access to such a diploid $V$. darrowi $\mathrm{x}$ tetraploid $V$. corymbosum-derived tetraploid population $(\mathrm{Qu}$ and Hancock, 1997) for use in comparative mapping studies with our population of diploid plants derived from $V$. darrowi $x$ V. caesariense Mackenz. (also known as diploid V. corymbosum).

Furthermore, the feasibility of using Agrobacterium tumefaciens to transform blueberry has been demonstrated. We have established the susceptibility of highbush blueberry to infection by Agrobacterium (Rowland, 1990), identified a highbush blueberry cultivar particularly amenable to regeneration from leaf disks (Rowland and Ogden, 1992, 1993), and significantly improved efficiency of shoot regeneration from leaf disks (Rowland and Ogden, 1992, 1993). Thus, if genes that control chilling requirement or cold hardiness are isolated, it should be possible to use such gene constructs in transformation experiments to test their effects on chilling requirement and cold hardiness.

\section{CONSTRUCTION OF GENETIC LINKAGE MAPS FOR BLUEBERRY}

\section{Description of mapping populations}

We previously reported the construction of an initial genetic linkage map for diploid blueberry using a population segregating for chilling requirement, which resulted from a testcross between an $\mathrm{F}_{1}$ interspecific hybrid (V. darrowi $\times$ V. elliottii Chapm.) and another $V$. darrowi clone (Rowland and Levi, 1994). A testcross was used because diploid blueberry tolerates little inbreeding; therefore, true $\mathrm{F}_{2}$ or backcrosses cannot be easily generated for mapping. The map currently comprises 72 randomly amplified polymorphic DNA(RAPD) markers mapped to 12 linkage groups (in agreement with the basic blueberry chromosome number), and covers a total genetic distance of over $950 \mathrm{cM}$, with a range of 3-30 cM between adjacent markers.

Because our interests have expanded to include identification of markers linked to both cold hardiness and chilling requirement, we have recently focused on developing maps for two testcross populations that segregate for both characteristics. These populations were generated by backcrossing $V$. darrowi $\times$ V. caesariense hybrids (Fla4B x W85-20) to another V. darrowi and another V. caesariense (Rowland et al., 1995). Diploid $V$. darrowi is a southern evergreen, lowbush species whose habitat ranges from Florida to Louisiana. V. darrowi has been used extensively in blueberry breeding programs to introduce low chilling requirement into the typically high-chilling highbush background (Galletta and Ballington, 1996; Hancock and Draper, 1989; Hancock et al., 1995). The original V. darrowi parent plant used in our diploid mapping populations, Fla4B, was, in fact, the primary clone used in the USDA blueberry breeding program to develop lowchilling southern highbush cultivars. Fertile $F_{1}$ hybrids $(4 x)$ of Fla4B (2x) and $V$. corymbosum ( $4 \mathrm{x})$ cultivars, such as 'Bluecrop' and 'Bluetta', are relatively easy to produce for breeding purposes, because some $V$. darrowi clones, such as Fla4B, produce a relatively high frequency of unreduced gametes (Draper et al., 1982; Ortiz et al., 1992). Fla4B, collected from Ocala, Fla., has a low chilling requirement and is relatively cold-sensitive (Arora et al., 1998; Rowland et al., 1995). Diploid V. caesariense is a highbush, deciduous species that is considered to be either the same species as, or the most closely related species to, the cultivated tetraploid highbush, V. corymbosum (Galletta and Ballington, 1996; Luby et al., 1991). The V. caesariense clone W85-20, the other original parent plant in our diploid mapping populations, was collected from New Jersey. It has a higher chilling requirement than does Fla4B and is more cold-hardy (Arora et al., 1998; Rowland et al., 1995).

To generate the testcross populations, three $F_{1}$ plants were crossed to plants of $V$. darrowi (NJ88-13-15) and V. caesariense (W85-23), whose chilling requirements and cold hardiness levels were similar to those of the original parents. Chilling requirements [for the $V$. darrowi parents (Fla4B and NJ88-13-15)], calculated in 1996 and 1997 and averaged over the 2 years, are 386 and 260 chill units (CU), respectively. Here, chill units are defined as the number of hours plants were exposed to temperatures from 0 to $7^{\circ} \mathrm{C}$. Chilling requirements for the V. caesariense parents (W85-20 and W85-23) are 1411 and $1188 \mathrm{CU}$, respectively. Cold hardiness $\left(\mathrm{LT}_{50} \mathrm{~s}\right)$ for Fla4B and NJ88-13-15 are -11.3 and $-14.3^{\circ} \mathrm{C}$, respectively, whereas cold hardiness for the W8520 and $\mathrm{W} 85-23$ are -21.0 and $-21.5^{\circ} \mathrm{C}$, respectively (Arora et al., 1998). $V$. darrowi and $V$. caesariense testcrosses currently comprise $\approx 150$ plants each.

Because of differences in the chilling requirements and levels of cold hardiness of the $V$. darrowi and $V$. caesariense parent plants, the diploid mapping populations were expected to segregate for these traits, and thus would be well suited for identifying markers linked to genes controlling chilling requirement and cold hardiness. The fact

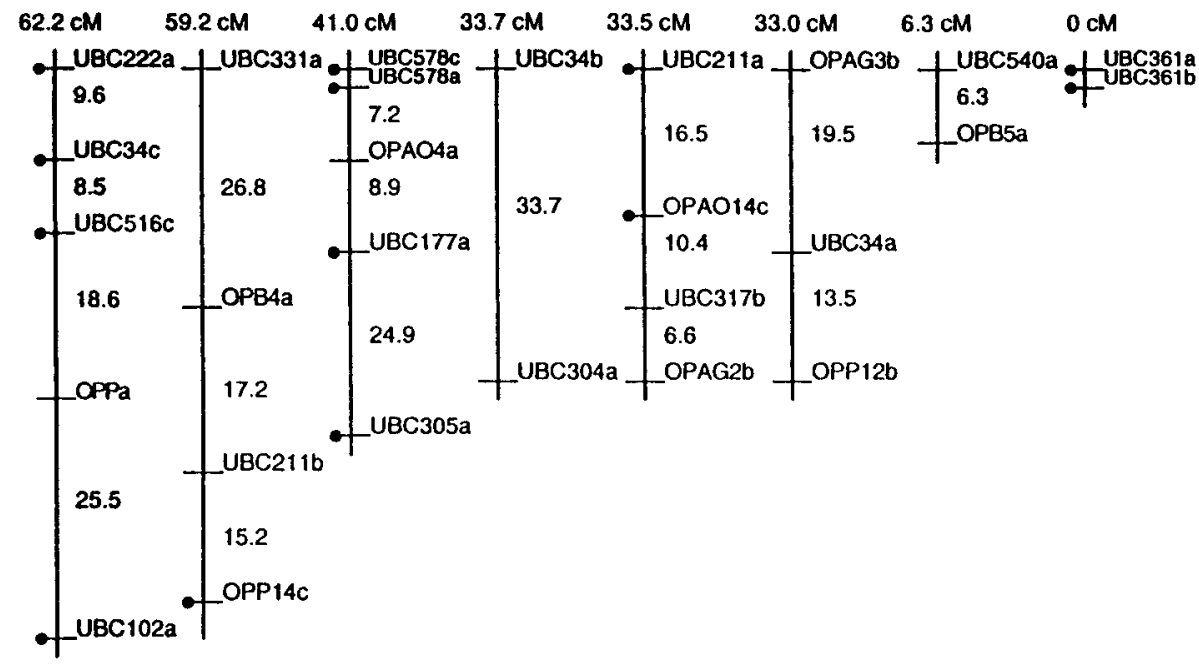

Fig. 1. RAPD-based genetic linkage map of blueberry derived from a cross between diploid $V$. darrowi $x$ V. caesariense and $V$. darrowi. Linkage groups are displayed from longest to shortest. Marker names and distances between adjacent markers (in cM) are shown to the right of each linkage group. If no distance is indicated between markers, then no recombination was detected between those markers. Marker names are based on the origin of the primers (either UBC for Univ. of British Columbia or OP for Operon), followed by the primer names (assigned by UBC or Operon), followed by a letter. Letters are assigned in alphabetical order beginning with the highest molecular weight marker generated from a particular primer and ending with the lowest molecular weight marker. Bold lines between markers indicate markers whose order cannot be deduced with good certainty. Symbols $(\bullet)$ indicate markers that were mapped in both the $V$. darrowi and $V$. caesariense testcross populations. 
that these populations do segregate for these traits has been confirmed (see following section).

\section{Genetic linkage maps for $V$. darrowi and $V$. caesariense testcrosses}

Currently, we have collected segregation data on 89 RAPD markers using an initial 53 plants of the $V$. darrowi testcross and 54 plants of the $V$. caesariense testcross. Of the 89 RAPD markers, 54 could be followed in the $V$. darrowi testcross, 76 in the $V$. caesariense testcross, and 41 in both testcross populations. Using the MAPMAKER program (Lander et al., 1987), 27 of the 54 markers followed in the $V$. darrowi testcross have been assigned to eight linkage groups (Fig. 1) and 37 of the 76 markers followed in the $V$. caesariense testcross to 12 linkage groups (Fig. 2). The number of markers assigned to the individual linkage groups ranges from two to five for the $V$. darrowi testcross and two to seven for the $V$. caesariense testcross. The distance between adjacent markers ranges from 6.3 to $33.7 \mathrm{cM}$ and 5.0 to $43.8 \mathrm{cM}$, for the $V$. darrowi and $V$. caesariense testcrosses, respectively. Thirteen of the markers have been mapped in both populations. At this stage, the number of shared markers is too few to allow us to superimpose the maps; however, the shared markers appear to group similarly in the two populations.

\section{GENETIC CONTROL OF CHILLING REQUIREMENT AND COLD HARDINESS}

\section{Status of QTL and generation means analyses}

Although current genetic linkage maps for the $V$. darrowi and $V$. caesariense testcrosses are not saturated enough to map QTLs controlling chilling requirement and cold hardiness, data collected for these traits have been used in generation means analyses (Beaver and Mosjidis, 1988; Mather and Jinks, 1982) to evaluate different additive and epistatic models that may explain the gene action of the traits. In generation means analyses, joint scaling tests (Mather and Jinks, 1982) are used to investigate gene action for a given trait. These tests use parental, $\mathrm{F}_{1}$, and testcross populations' means and variances to estimate values for genetic components and nonallelic (epistatic) interactions of a cross. The estimates are then used to fit genetic models to the data that best explain differences among means for the various populations. The theoretical basis of the joint scaling tests is a linear model. The mean chilling requirement or cold hardiness $(X)$ of a generation can be described by the following linear equation: $X=m+$ $d+h+i+j+l$; where $m=$ means of all possible homozygotes, $d=$ additive component, $h=$ dominance component, $i=$ additive-additive interaction, $j=$ additive-dominance interaction, and $l=$ dominancedominance interaction. The coefficients of these components for various generations have been described (Mather and Jinks, 1982).

Data for both chilling requirement and cold hardiness have been used to test 18 genetic models that include components $m d, m h$, or $m d h$ in combination with one or more of the epistatic parameters $(i, j$, or $l)$. Our criteria for accepting a model are that the model must have a chisquare probability of 0.05 or greater and all of its genetic parameters must be significant, as judged by Student's $t$ tests.

\section{Genetic control of cold hardiness}

Results from generation means analysis of the cold hardiness data (Arora et al., 1998) are more straightforward than those from the chilling requirement data. Based on the criteria described above, cold hardiness data best fit a simple additive-dominance model $(m d h)$ of gene action (Table 1). Indeed, the observed means for the parental, $\mathrm{F}_{1}$, and testcross populations are not significantly different from, and almost identical to, the expected means predicted from the simple additive-dominance model (Table 2). Although both the genetic parameters $(d$ and $h)$ contribute significantly to the additive-dominance model, the $h$ (dominance-gene effect) parameter is only weakly significant $(P \leq 0.10)$ relative to the $d$ (additive-gene effect) parameter $(P \leq 0.05)$. Similar results have been obtained in other genetic studies. Watkins and Spangelo (1970) concluded that epistasis and dominance are not major factors in the cold tolerance of Malus sp., and that low temperature-induced bud damage is controlled by additive variance. In addition, Stone et al. (1993) concluded that cold acclimation ability

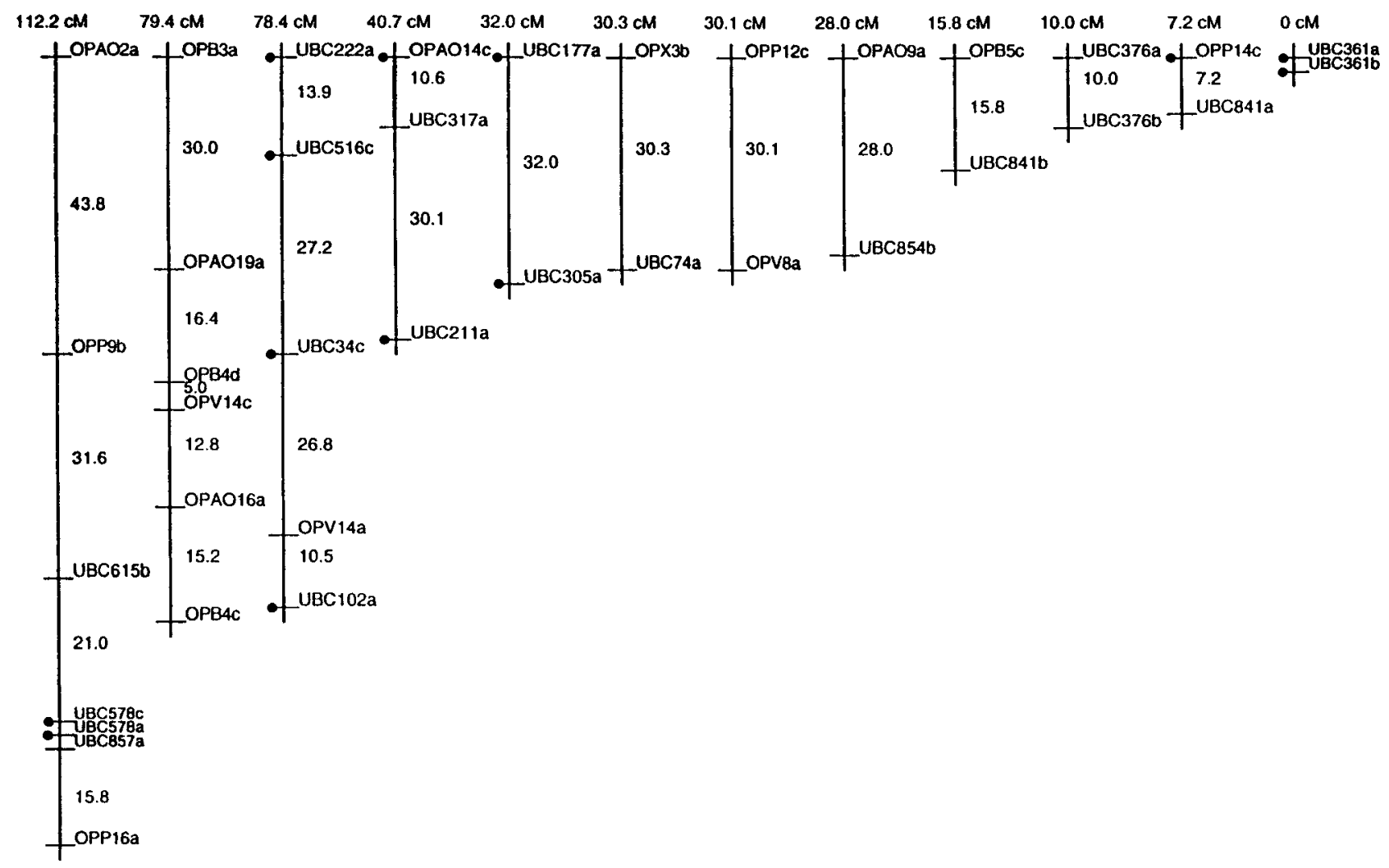

Fig. 2. RAPD-based genetic linkage map of blueberry derived from a cross between diploid V. darrowi $\times$ V. caesariense and V. caesariense. 
in Solanum species can be explained by a simple additive-dominance model of gene action, and that the additive component is more highly significant than the dominance component.

Degree of dominance (Falconer, 1989) of cold hardiness has also been evaluated in blueberry (Arora et al., 1998). Because the mean cold hardiness of the $\mathrm{F}_{1}$ population is $-14.7^{\circ} \mathrm{C}$-closer to the $V$. darrowi parent than to the V. caesariense parent (Table 2) - cold/ freeze-sensitivity appears to be partially dominant (or, conversely, cold hardiness is partially recessive). Similar conclusions were drawn by Stone et al. (1993), who noted that cold acclimation ability in Solanum is partially recessive. Our results are also analogous to those of Sutka (1981) who reported frost sensitivity in wheat to be partially dominant. Finally, the recovery of parental phenotypes in the relatively small number of testcross individuals analyzed thus far for cold hardiness (40-50 plants of each testcross) suggests that cold hardiness may be controlled by relatively few genes in blueberry (Arora et al., 1998). This, too, has been reported for Solanum species by Stone et al. (1993).

\section{Genetic control of chilling requirement}

In contrast to the cold hardiness results, generation means analysis of chilling requirement data failed to identify any models that accurately predict the chilling requirement means for the populations analyzed. Simple models lacking epistatic interactions or having only one epistatic component are significant. However, in all cases, one or more of the genetic parameters are not significantly different from zero. Therefore, no models are acceptable.

Several reasons can be offered for the lack of fit. First, it may be partially due to the relatively low chilling requirement mean values for the testcross populations (Table 3 ). The means of the $V$. darrowi and $V$. caesariense testcross populations are skewed more towards the $V$. darrowi parental and $\mathrm{F}_{1}$ populations, respectively, suggesting that low chilling requirement is a dominant trait. However, the mean for the $F_{1}$ population suggests a low degree of dominance, as the $F_{1}$ mean is approximately halfway between the means for the two parental populations. Theoretically, parental and $\mathrm{F}_{1}$ populations should be uniform and should exhibit less variation than the segregating testcross populations; however, we observed that the parental and $F_{1}$ generations exhibit considerable variation. Variances for parental and $F_{1}$ populations are approximately equal to or exceed the average variances for the testcross populations. These large variances are due, in part, to a discontinuous distribution of chilling requirement values. For example, the $\mathrm{F}_{1}$ generation of Fla4B $\times$ W85-20, comprised of nine plants, has four plants with chilling requirement values from 530-600 CU and five with values from 800-1010 CU. This discontinuous distribution is indicative of a segregating population. Similarly, the $V$. darrowi parental population, comprised of $14 \mathrm{~V}$. darrowi plants, has two plants whose chilling requirements are separated from the remainder of the population by over $600 \mathrm{CU}$. One of the assumptions of the generation means analysis is that the parents are homozygous for the trait of interest. Heterozygous parents with genes for high and low chilling requirement would result in the segregation of otherwise uniform populations and would invalidate generation means analysis. Hence, we propose that the lack of fit of the models that we tested is due to the segregation and nonuniformity of parental and $F_{1}$ generations.

Although we were unable to determine the gene action of chilling requirement from generation means analysis, we attempted to study the inheritance of this trait. Using the distribution of chilling requirement in the $F_{1}$ and testcross populations, we have evaluated mono- and digenic models for inheritance of chilling requirement that do not assume that the $V$. darrowi and $V$. caesariense parent plants are each homozygous for low chilling- and high chilling-determining genes. The simplest such model is that chilling requirement is controlled by one gene that is not fixed (i.e., it is heterozygous) in one of the parents. For example, if we assign the $V$. darrowi parent Fla4B the genotype Aa and the $V$. caesariense parent W85-20 the genotype aa, two classes of Fla4B x W85-20 $\mathrm{F}_{1} \mathrm{~s}$ would be expected, having the genotypes Aa and aa, which are identical to the parental genotypes. This model can be excluded because, although the $\mathrm{F}_{1} \mathrm{~s}$ can be divided into two distinct classes (530-600 and 800-1010 CU), they have chilling requirements
Table 1. Goodness of fit, from joint scaling tests, of various genetic models using cold hardiness data from a cross between Vaccinium darrowi and $V$. caesariense.

\begin{tabular}{lccc}
\hline Model $^{\mathrm{z}}$ & Chi-square value & $P$ & Component fit \\
\hline$m[d][h]$ & 0.97 & 0.62 & {$[\mathrm{~d}]^{* *}[\mathrm{~h}]^{*}$} \\
$m[d][h][i]$ & 0.34 & 0.56 & {$[\mathrm{~d}]^{*}$} \\
$m[d][h][j]$ & 0.59 & 0.44 & \\
$m[d][h][l]$ & 0.34 & 0.56 & {$[\mathrm{~d}]^{*}$} \\
$m[d][i]$ & 4.38 & 0.11 & {$[\mathrm{~d}]^{*}$} \\
$m[d][l]$ & 0.36 & 0.84 & {$[\mathrm{~d}]^{*}$} \\
$m[d][i][l]$ & 0.34 & 0.56 & {$[\mathrm{~d}]^{*}$} \\
$m[d][j][l]$ & 0.02 & 0.89 & \\
\hline
\end{tabular}

${ }^{\mathrm{z}} m=$ estimate of the mean of all possible homozygotes, $d=$ additive component, $h=$ dominance component, $i=$ additive-additive interaction, $j=$ additivedominance interaction, and $l=$ dominance-dominance interaction. Models shown are those in which chi-square probability $(P)$ is greater than or equal to 0.05 . Models in which $P \geq 0.05$ and each individual component of the model is significant as judged by $t$ tests were accepted. Only the simple additivedominance model $(m d h)$ of gene action fits these criteria (Arora et al., 1998).

${ }^{*},{ }^{* *}$ Component significant at $P \leq 0.10$ or 0.05 , respectively.

Table 2. Observed (determined by freeze-thaw tests) and expected (based on simple additive-dominance model of gene action) means for cold hardiness $\left(\mathrm{LT}_{50} \mathrm{~s},{ }^{\circ} \mathrm{C}\right)$ for parental $(\mathrm{P}), \mathrm{F}_{1}$, and testcross (TC) generations of a cross between $V$. darrowi and $V$. caesariense ${ }^{\mathrm{z}}$.

\begin{tabular}{lcc}
\hline \hline Generation & Observed mean \pm sE & Expected mean \\
\hline $\mathrm{P}_{1}($ V. darrowi $)$ & $-13.0 \pm 1.00$ & -13.1 \\
$\mathrm{TC}_{1}\left(\mathrm{~F}_{1} \times\right.$ V. darrowi $)$ & $-14.0 \pm 0.43$ & -13.9 \\
$\mathrm{~F}_{1}$ & $-14.7 \pm 0.33$ & -14.8 \\
$\mathrm{TC}_{2}\left(\mathrm{~F}_{1} \times\right.$ V. caesariense $)$ & $-18.0 \pm 0.30$ & -17.8 \\
$\mathrm{P}_{2}($ V. caesariense $)$ & $-20.0 \pm 1.00$ & -20.8 \\
\hline
\end{tabular}

${ }^{\mathrm{z}}$ Adapted from Arora et al. (1998).

Table 3. Observed mean chilling requirements $(\mathrm{CU})$, measured in 1997, for parental $(\mathrm{P}), \mathrm{F}_{1}$, and testcross (TC) generations of a cross between $V$. darrowi and V. caesariense.

\begin{tabular}{lcc}
\hline$\overline{\text { Generation }}$ & $\mathrm{N}^{\mathrm{z}}$ & Observed mean \\
\hline $\mathrm{P}_{1}($ V. darrowi $)$ & 14 & 425 \\
$\mathrm{TC}_{1}\left(\mathrm{~F}_{1} \times\right.$ V. darrowi $)$ & 54 & 375 \\
$\mathrm{~F}_{1}$ & 9 & 751 \\
$\mathrm{TC}_{2}\left(\mathrm{~F}_{1} \times\right.$ V. caesariense $)$ & 49 & 817 \\
$\mathrm{P}_{2}($ V. caesariense $)$ & 12 & 1005 \\
\hline${ }^{2} \mathrm{~N}=$ number of plants evaluated in each population.
\end{tabular}

that fall between those of the parents (Table 3).

The next simplest model is that chilling requirement is controlled by two genes ( $\mathrm{A}$ and $\mathrm{B}$ ) with equal effects and that $\mathrm{A}$ is fixed in the parent populations and $B$ is not fixed. Based on the range of values for chilling requirement, we assigned each allele, a or b, as contributing $300 \mathrm{CU}$ toward the chilling requirement, and proposed that Fla4B and W85-20 have the genotypes AABb and aabb, respectively. In this case, Fla4B would have an expected chilling requirement of $300 \mathrm{CU}$ and W85-20 1200 CU. Two classes of Fla4B x W85-20 $\mathrm{F}_{1}$ s would result, having the genotypes $\mathrm{AaBb}$ and $\mathrm{Aabb}$ and chilling requirements of 600 and $900 \mathrm{CU}$, respectively, at a segregation ratio of $1: 1$. The theoretical mean for the $F_{1}$ population would be $750 \mathrm{CU}$. The observed segregation ratio for the nine $\mathrm{F}_{1} \mathrm{~s}$ is $4(530-600 \mathrm{CU}): 5$ (800-1010 CU) and fits a 1:1 segregation ratio. The observed mean is $750.7 \mathrm{CU}$. If we continue on with this model (Table 4), we find that it fairly accurately predicts the segregation ratios observed in the testcross populations, as well, with one exception. In crosses involving the high chilling $\mathrm{F}_{1} \mathrm{~s}$ and NJ88-13-15 as the $V$. darrowi testcross parent, the chilling requirements of the progeny are skewed lower than predicted by the model, with a segregation ratio of about $3: 1$ ( $\leq 450 \mathrm{CU}$ : $451-750 \mathrm{CU})$ rather than the predicted $1: 1$ ratio. This could possibly be explained by the presence of additional modifier genes in NJ88-13-15 that tend to reduce the chilling requirements of progeny. However, this phenomenon is not observed in crosses involving the low chilling $F_{1}$ class and NJ88-13-15. The discrepancies may also simply be due to the small population size. More accurate segregation ratios will await the 
Table 4. Expected and observed genotypes, chilling requirements, segregation ratios, and means for chilling requirement model that assumes that chilling requirement is controlled by two genes ( $\mathrm{A}$ and $\mathrm{B}$ ) with equal and additive effects, and each allele (a or b) is assumed to contribute $300 \mathrm{CU}$ toward the chilling requirement.

\begin{tabular}{|c|c|c|c|c|}
\hline Populations & $\begin{array}{c}\text { Expected genotypes } \\
\text { and segregation ratios }\end{array}$ & $\begin{array}{c}\text { Expected CRs }{ }^{z}, \\
\text { segregation ratios, and means }\end{array}$ & $\begin{array}{c}\text { Observed CRs, } \\
\text { segregation ratios, and means }\end{array}$ & $\left(\chi^{2}, P\right)^{\mathrm{y}}$ \\
\hline \multicolumn{5}{|l|}{$\mathrm{P}_{1}$} \\
\hline Fla4B & $\mathrm{AABb}$ & 300 & 386 & \\
\hline NJ88-13-15 & $\mathrm{AABB}^{\mathrm{x}}$ & minimum, 260 & 260 & \\
\hline \multicolumn{5}{|l|}{$\underline{\mathrm{P}_{2}}$} \\
\hline $\mathrm{W} 85-20$ & aabb & 1200 & 1411 & \\
\hline W85-23 & $\mathrm{aaBb}$ & 900 & 1188 & \\
\hline \multicolumn{5}{|l|}{$\mathrm{F}_{1}$} \\
\hline \multirow[t]{2}{*}{ Fla4B x W85-20 } & $1(\mathrm{AaBb}): 1(\mathrm{Aabb})$ & $1(600): 1(900)$ & $4(530-600): 5(800-1010)$ & $(0.11,0.74)$ \\
\hline & & Mean $=750$ & Mean $=750.7$ & \\
\hline \multicolumn{5}{|l|}{$\underline{\mathrm{TC}_{1}}$} \\
\hline \multirow[t]{2}{*}{$\overline{\mathrm{F}_{1}} \mathrm{AaBb} \times \mathrm{NJ} 88-13-15$} & 1 (AABB): $1(\mathrm{AaBB}):$ & $3(260$ or 300$): 1(600)$ & $9(\leq 450): 5(451-750)$ & $(0.86,0.35)$ \\
\hline & $1(\mathrm{AABb}): 1(\mathrm{AaBb})$ & Mean $=365$ & Mean $=418.1$ & \\
\hline \multirow[t]{2}{*}{$\mathrm{F}_{1}$ Aabb x NJ88-13-15 } & $1(\mathrm{AABb}): 1(\mathrm{AaBb})$ & $1(300): 1(600)$ & $31(\leq 450): 9(451-750)$ & $(10.1,0.0015)$ \\
\hline & & Mean $=450$ & Mean $=360.2$ & \\
\hline \multicolumn{5}{|l|}{$\underline{\mathrm{TC}_{2}}$} \\
\hline \multirow[t]{2}{*}{$\overline{\mathrm{F}_{1}} \mathrm{AaBb} \times \mathrm{W} 85-23$} & $1(\mathrm{AaBB}): 1(\mathrm{aaBB}):$ & $1(300): 3(600):$ & $3(\leq 450): 9(451-750)$ : & \\
\hline & $2(\mathrm{AaBb}): 2(\mathrm{aaBb}):$ & 3 (900): 1 (1200) & $9(751-1050): 4(1051-1350)$ & $(0.28,0.96)$ \\
\hline \multirow[t]{3}{*}{$\mathrm{F}_{1} \mathrm{Aabb} \times \mathrm{W} 85-23$} & $1(\mathrm{AaBb}): 1(\mathrm{aaBb}):$ & $1(600): 2$ (900): & $3(451-750): 16(751-1050)$ & \\
\hline & 1 (Aabb): 1 (aabb) & $1(1200)$ & $5(1051-1350)$ & $(3.00,0.22)$ \\
\hline & & Mean $=900$ & Mean $=879.3$ & \\
\hline
\end{tabular}

${ }^{\mathrm{z}} \mathrm{CR}=$ chilling requirement, expressed in chill units (CU).

${ }^{y} \mathrm{~A}$ chi-square test was used to determine the goodness of fit of the observed segregation ratios to the expected ones. $P \leq 0.05$ was considered a significant deviation from the expected values.

${ }^{\mathrm{x}}$ For genotype $\mathrm{AABB}$, a minimum chilling requirement of $260 \mathrm{CU}$ is assumed.

maturation of more progeny plants and determinations of their chilling requirements. We do not presently exclude this model, however, to explain chilling requirement gene action in blueberry.

\section{CHILLING/COLD-RESPONSIVE GENES IN BLUEBERRY}

\section{Identification of chilling-responsive proteins}

To identify proteins associated with low-temperature exposure or "chilling," we have examined changes in protein levels associated with CU accumulation in blueberry floral buds (Muthalif and Rowland, 1994a, 1994b). From profiles of soluble proteins, levels of three proteins of 65,60 , and $14 \mathrm{kD}$ were observed to increase with $\mathrm{CU}$ accumulation such that they become the predominant proteins visible on SDS gels. Further characterization by partial sequence analysis and immunoblot analysis has revealed that they belong to the dehydrin family of proteins (Muthalif and Rowland, 1994a, 1994b). Since that time, additional dehydrin proteins have been identified in blueberry, with molecular weights of $\approx 40 \mathrm{kD}$ (Arora et al., 1997a), $22 \mathrm{kD}$ (Muthalif and Rowland, 1995), and $10 \mathrm{kD}$ (Muthalif and Rowland, 1994a). Presence and sizes of these additional dehydrins, however, vary depending on species and cultivar.

Dehydrins are a group of heat-stable, glycine-rich plant proteins that are induced by environmental stimuli that result in dehydration, including drought, low temperature, salinity, and seed maturation (Close, 1996; Close et al., 1993). Another characteristic of dehydrins is the presence of a highly conserved, lysine-rich, 15-amino-acid sequence (consensus sequence EKKGIMDKIKEKLPG), referred to as the $\mathrm{K}$ box, which is often repeated several times throughout the protein (Close, 1996; Close et al., 1993). A number of physiological studies have demonstrated a correlation between accumulation of dehydrins and tolerance to environmental stresses leading to dehydration. The first evidence for a causal relationship between such genes and freezing tolerance was reported earlier this year from work on Arabidopsis (Jaglo-Ottosen et al., 1998).

\section{Cloning and sequencing members of the dehydrin gene family}

Peptide sequence information from the 65 and $60 \mathrm{kD}$ dehydrins of blueberry has been used to synthesize degenerate DNA primers for PCR amplification of a part of the gene(s) encoding these or other dehydrins. One pair of primers amplified a $174 \mathrm{bp}$ fragment; sequence analysis confirmed that the fragment was derived from a dehydrin gene (Rowland et al., 1996). The 174 bp fragment has been used to screen a cDNA library (prepared from RNA from cold-acclimated blueberry floral buds) and has resulted, to date, in the isolation of one cDNA clone with a $2.0 \mathrm{~kb}$ insert (Rowland and Arora, 1997). The cDNA has been sequenced and found to be a full length clone encoding a $\mathrm{K}_{5}$ type of dehydrin (contains $5 \mathrm{~K}$ boxes). From the deduced protein sequence and coupled in vitro transcription/translation reactions, the clone appears to encode a dehydrin with a molecular weight of $\approx 40 \mathrm{kD}$. The dehydrin cDNA hybridizes on RNA blots to two chilling-responsive messages of 2.0 and $0.5 \mathrm{~kb}$ (Fig. 3), the $2.0 \mathrm{~kb}$ message being the same size as the clone and the $0.5 \mathrm{~kb}$ message being of an appropriate

\section{TIFBLUE BLUECROP}

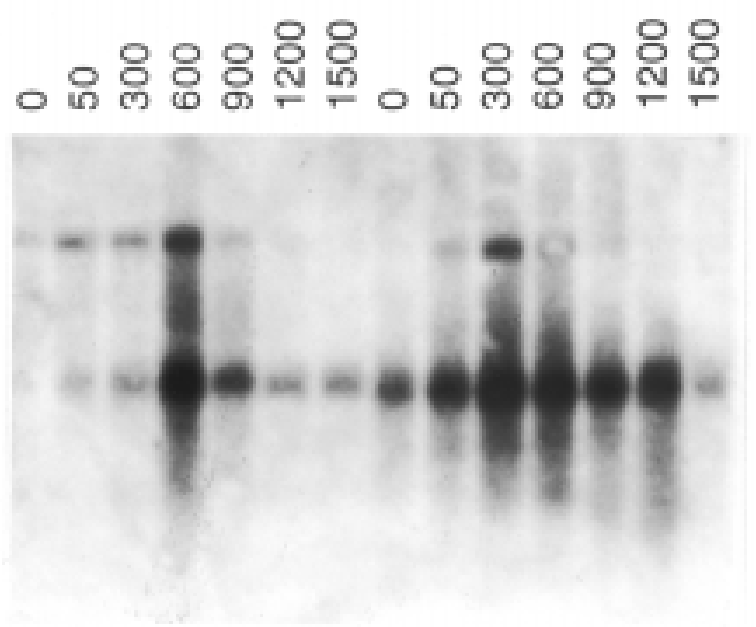

Fig. 3. Northern blot of total RNA extracted from blueberry cultivars 'Tifblue' and 'Bluecrop' and hybridized with the $2.0 \mathrm{~kb}$ dehydrin cDNA. RNA was extracted from floral buds collected from field plants after different lengths of chilling (from 0 to $1500 \mathrm{CU}$ ) and equal amounts were loaded in each lane. 
size to possibly encode the $14 \mathrm{kD}$ dehydrin. An examination of dehydrin mRNA expression patterns during the winter in two blueberry cultivars, 'Bluecrop' and 'Tifblue', with different freezing tolerances revealed that both the 2.0 and $0.5 \mathrm{~kb}$ messages increase more rapidly and to higher levels in the more cold-hardy 'Bluecrop' than in the cold-sensitive 'Tifblue'; in addition, the $0.5 \mathrm{~kb}$ message declines relatively faster in 'Tifblue' than in 'Bluecrop'. Also, the dehydrin cDNA hybridizes on DNA blots to an RFLP marker suitable for mapping in our diploid blueberry populations, which segregate for chilling requirement and cold hardiness. We are currently attempting to use this clone as a probe to isolate and characterize additional members of the dehydrin gene family.

\section{Relationship of dehydrins to dormancy or cold hardiness in woody perennials}

Because cold acclimation and development of dormancy, as well as deacclimation and release from dormancy, occur simultaneously in woody perennials, it is impossible from the work described above (Muthalif and Rowland, 1994a, 1994b) to discern whether the major dehydrins of blueberry are more closely associated with cold acclimation or with the development or maintenance of dormancy. In a recent study, we have carried out a series of physiological experiments to better make this distinction (Arora et al., 1997a). These experiments utilized a temperature treatment of $15{ }^{\circ} \mathrm{C}$ day $/ 12^{\circ} \mathrm{C}$ night for 2 weeks to trigger deacclimation in dormant, cold-acclimated plants (plants that had only $50 \%$ of their chilling requirements satisfied). This treatment had no effect on dormancy status (negation of CU) while resulting in loss of cold hardiness (deacclimation). Moreover, for blueberry cultivars that have undergone this deacclimation treatment, levels of the dehydrins decrease to about the levels in nonacclimated plants (Fig. 4). Thus, we conclude from these experiments that dehydrin levels are more closely associated with cold hardiness transitions than with changes in dormancy status per se.

\section{CONCLUSIONS}

Because of limited understanding concerning chilling requirement and cold hardiness in woody perennials, we are using a combination of genetic, molecular, and physiological approaches to investigate genetic control and regulation of these traits in blueberry. Genetic and molecular approaches are being used to map QTLs controlling chilling requirement and cold hardiness and to determine their mode(s) of action. To achieve the mapping goal, RAPD-based genetic linkage maps are being constructed using two diploid testcross populations, segregating for chilling requirement and cold hardiness. To date, 27 RAPD markers have been assigned to eight linkage groups in the $V$. darrowi testcross and 37 RAPD markers have been assigned to 12 linkage groups in the $V$. caesariense testcross population. Chilling requirement and cold hardiness data obtained from the mapping populations have been used in generation means analyses to evaluate different models of gene action. Data for cold hardiness best fit a simple additive-dominance model of gene action, whereas data for chilling requirement do not. The lack of fit of the chilling requirement data is apparently due to at least one of the parental populations not being homozygous for one or more genes controlling chilling requirement. By examining segregation ratios of chilling requirement in the $F_{1}$ and testcross populations, as well as the goodness of fit to some relatively simple genetic models that do not assume homozygosity of the parental populations for chilling requirement-determining genes, we have developed a two-gene model that fairly accurately predicts the observed segregation ratios. In its simplest form, this model assumes that two genes with equal and additive effects control chilling requirement.

Concomitantly, molecular and physiological approaches are being used to identify and isolate chilling-responsive genes from blueberry and determine their relationship to chilling requirement or cold acclimation. Major chilling-responsive proteins found in blueberry flower buds have been identified as dehydrins, and one of the members of the dehydrin gene family has been cloned and sequenced. Using an experimental approach that triggers deacclimation without affecting dormancy status of buds, we have also established that the dehydrins are associated with changes in cold hardiness rather than in dormancy status.

Finally, once chilling-responsive genes are cloned, they can be mapped to determine if they are associated with loci identified from QTL analyses that control chilling requirement and cold hardiness. In addition, gene constructs can be used in transformation experiments to determine their effect(s) on these characteristics. These experiments will allow us to more definitively establish the relationship between chilling-responsive genes and the determination of chilling requirement and cold hardiness.

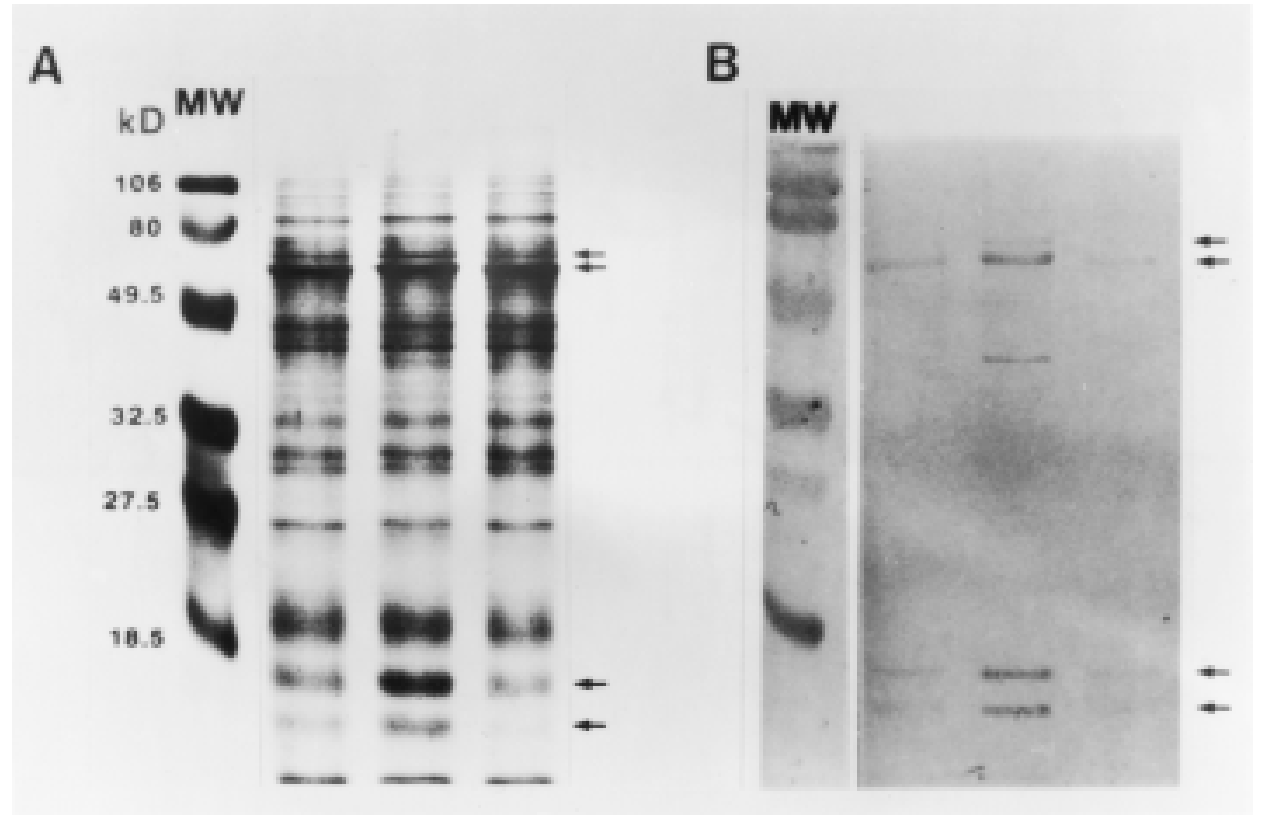

Fig. 4. (A) SDS-PAGE protein profiles of 'Tifblue' blueberry buds at various levels of cold hardiness and CU accumulation. Protein samples (three lanes) correspond to various treatments as follows: lane 1, nonacclimated/0 CU; lane 2, cold acclimated/50\% of chilling requirement satisfied; lane 3, deacclimated/50\% of chilling requirement satisfied. Thirty micrograms of protein was loaded in each lane. To the left, molecular weight markers are shown. Arrows to the right mark the $65,60,14$, and $10 \mathrm{kD}$ dehydrins. (B) Western blot analysis of proteins in (A), using anti-dehydrin antiserum. Five micrograms of protein was loaded in each lane (Arora et al., 1997b). 


\section{Literature Cited}

Arora, R., L.J. Rowland, and G.R. Panta. 1997a. Chill-responsive dehydrins in blueberry: Are they associated with cold hardiness or dormancy transitions? Physiol. Plant. 101:8-16.

Arora, R., L.J. Rowland, G.R. Panta, C-C. Lim, J.S. Lehman, and N. Vorsa. 1998. Genetic control of cold hardiness in blueberry, p. 99-106. In: P.H. Li and T.H.H. Chen (eds.). Plant cold hardiness: Molecular biology, biochemistry, and physiology. Plenum, New York.

Arora, R., M.E. Wisniewski, and L.J. Rowland. 1997b. Low temperatureinduced expression of dehydrins in deciduous fruit crops and their relation to cold acclimation and/or dormancy. Acta Hort. 441:175-182.

Beaver, R.J. and J.A. Mosjidis. 1988. Important considerations in the analysis of generation means. Euphytica 39:233-235.

Close, T.J. 1996. Dehydrins: Emergence of a biochemical role of a family of plant desiccation proteins. Physiol. Plant. 97:795-803.

Close, T.J., R.D. Fenton, A. Yang, R. Asghar, D.A. DeMason, D.E. Crone, N.C. Meyer, and F. Moonan. 1993. Dehydrin: The protein, p. 104-118. In: T.J. Close and E.A. Bray (eds.). Plant responses to cellular dehydration during environmental stress. Amer. Soc. Plant Physiol., Rockville, Md.

Costich, D.E., R. Ortiz, T.R. Meagher, L.P. Bruderle, and N. Vorsa. 1993. Determination of ploidy level and nuclear DNA content in blueberry by flow cytometry. Theor. Appl. Genet. 86:1001-1006.

Draper, A.D., G.J. Galletta, and J.R. Ballington. 1982. Breeding methods for improving southern tetraploid blueberries. J. Amer. Soc. Hort. Sci. 96:791792.

Falconer, D.S. 1989. Introduction to quantitative genetics. 3rd ed. Wiley, New York.

Finn, C.E., J.J. Luby, and D.K. Wildung. 1990. Half-high blueberry cultivars. Fruit Var. J. 44:63-68.

Galletta, G.J. and J.R. Ballington. 1996. Blueberries, cranberries, and lingonberries, p. 1-107. In: J. Janick and J.N. Moore (eds.). Fruit breeding. Vol. 2. Wiley, New York.

Hancock, J.F. and A.D. Draper. 1989. Blueberry culture in North America. HortScience 24:551-556.

Hancock, J.F., W.A. Erb, B.L. Goulart, and J.C. Scheerens. 1995. Utilization of wild blueberry germplasm: The legacy of Arlen Draper. J. Small Fruit Viticult. 3:1-16.

Hokanson, S. and J.F. Hancock. 1993. The common lowbush blueberry, Vaccinium angustifolium Aiton, may be an autopolyploid. Can J. Plant Sci. 73:889-891

Jaglo-Ottosen, K.R., S.J. Gilmour, D.G. Zarka, O. Schabenberger, and M.F. Thomashow. 1998. Arabidopsis $C B F 1$ overexpression induces $C O R$ genes and enhances freezing tolerance. Science 280:104-106.

Krebs, S.L. and J.F. Hancock. 1992. Tetrasomic inheritance of isoenzyme markers in the highbush blueberry, Vaccinium corymbosum L. Heredity 63:11-18.

Lander, E.S., P. Green, J. Abrahamson, A. Barlow, M.J. Daly, S.E. Lincoln, and L. Newburg. 1987. MAPMAKER, an interactive computer package for constructing primary genetic linkage maps of experimental and natural populations. Genomics 1:185-199.

Lang, G.A., J.D. Early, G.C. Martin, and R.L. Darnell. 1987. Endo-, para-, and ecodormancy: Physiological terminology and classification for dormancy research. HortScience 22:371-377.

Luby, J.J., J.R. Ballington, A.D. Draper, K. Pliszka, and M.E. Austin. 1991.
Blueberries and cranberries (Vaccinium). Acta Hort. 290:391-456.

Luby, J.J., D.K. Wildung, C. Stushnoff, S.T. Munson, P.E. Read, and E.E. Hoover. 1986. 'Northblue', 'Northsky', and 'Northcountry' blueberries. HortScience 21:1240-1242.

Mather, S.K. and J.L. Jinks. 1982. Biometrical genetics: The study of continuous variation. 3rd ed. Chapman and Hall, London.

Moore, J.N. 1993. The blueberry industry of North America. Acta Hort. 346:15-26.

Muthalif, M.M. and L.J. Rowland. 1994a. Identification of dehydrin-like proteins responsive to chilling in floral buds of blueberry (Vaccinium section Cyanococcus). Plant Physiol. 104:1439-1447.

Muthalif, M.M. and L.J. Rowland. 1994b. Identification of chilling responsive proteins from floral buds of blueberry. Plant Sci. 101:41-49.

Muthalif, M.M. and L.J. Rowland. 1995. The search for chilling-responsive proteins in blueberry continues. J. Small Fruit Viticult. 3:53-60.

Ortiz, R., N. Vorsa, L.P. Bruederle, and T. Laverty. 1992. Occurrence of unreduced pollen in diploid blueberry species, Vaccinium sect. Cyanococcus. Theor. Appl. Genet. 85:55-60.

Powell, L.E. 1987. Hormonal aspects of bud and seed dormancy in temperatezone woody plants. HortScience 22:845-850.

$\mathrm{Qu}, \mathrm{L}$. and J.F. Hancock. 1995. Nature of $2 \mathrm{n}$ gamete formation and mode of inheritance in interspecific hybrids of diploid Vaccinium darrowi and tetraploid V. corymbosum. Theor. Appl. Genet. 91:1309-1315.

Qu, L. and J.F. Hancock. 1997. Randomly amplified polymorphic DNA(RAPD-) based genetic linkage map of blueberry derived from an interspecific cross between diploid Vaccinium darrowi and tetraploid V. corymbosum. J. Amer. Soc. Hort. Sci. 122:69-73.

Rowland, L.J. 1990. Susceptibility of blueberry to infection by Agrobacterium tumefaciens. HortScience 25:1659.

Rowland, L.J. and R. Arora. 1997. Proteins related to endodormancy (rest) in woody perennials. Plant Sci. 126:119-144.

Rowland, L.J. and A. Levi. 1994. RAPD-based genetic linkage map of blueberry derived from a cross between diploid species (Vaccinium darrowi X V. elliottii). Theor. Appl. Genet. 87:863-868.

Rowland, L.J., A. Levi, R. Arora, E.L. Ogden, M.M. Muthalif, N. Vorsa, R.G. Novy, and M.E. Wisniewski. 1995. Progress toward identifying markers linked to genes controlling chilling requirement and cold hardiness in blueberry. J. Small Fruit Viticult. 3:39-52.

Rowland, L.J., M.M. Muthalif, A. Levi, and R. Arora. 1996. Cloning and expression of dehydrin genes in blueberry. HortScience 31:585.

Rowland, L.J. and E.L. Ogden. 1992. Use of a cytokinin conjugate for efficient shoot regeneration from leaf sections of highbush blueberry. HortScience 27:1127-1129.

Rowland, L.J. and E.L. Ogden. 1993. Efficient shoot regeneration from leaf sections of highbush blueberry suitable for use in Agrobacterium-mediated transformations. Acta Hort. 336:193-197.

Stone, J.M., J.P. Palta, J.B. Bamberg, L.S. Weiss, and J.F. Harbage. 1993. Inheritance of freezing resistance in tuber-bearing Solanum species: evidence for independent genetic control of nonacclimated freezing tolerance and cold acclimation ability. Proc. Natl. Acad. Sci. USA 90:78697873.

Sutka, J. 1981. Genetic studies of frost resistance in wheat. Theor. Appl. Genet. 59:145-152.

Watkins, R. and L.P.S. Spangelo. 1970. Components of genetic variance for plant survival and vigor of apple trees. Theor. Appl. Genet. 40:195-203. 